\title{
Benthic biomass size spectra in shelf and deep-sea sediments
}

\author{
B. A. Kelly-Gerreyn ${ }^{1, *}$, A. P. Martin ${ }^{1}$, B. J. Bett ${ }^{1}$, T. R. Anderson ${ }^{1}$, J. I. Kaariainen ${ }^{1}$, C. E. Main ${ }^{1}$, C. J. Marcinko ${ }^{1}$, \\ and A. Yool ${ }^{1}$ \\ ${ }^{1}$ National Oceanography Centre, European Way, Southampton, SO14 3ZH, UK \\ *now at: Bureau of Meteorology, 700 Collins St., Docklands VIC 3008, Australia
}

Correspondence to: A. P. Martin (adrian.martin@noc.ac.uk)

Received: 29 November 2013 - Published in Biogeosciences Discuss.: 14 January 2014

Revised: 7 October 2014 - Accepted: 9 October 2014 - Published: 26 November 2014

\begin{abstract}
The biomass distributions of marine benthic metazoans (meio- to macro-fauna, $1 \mu \mathrm{g}-32 \mathrm{mg}$ wet weight) across three contrasting sites were investigated to test the hypothesis that allometry can consistently explain observed trends in biomass spectra. Biomass (and abundance) size spectra were determined from observations made at the Faroe-Shetland Channel (FSC) in the Northeast Atlantic (water depth $1600 \mathrm{~m}$ ), the Fladen Ground (FG) in the North Sea $(150 \mathrm{~m})$, and the hypoxic Oman Margin $(\mathrm{OM})$ in the Arabian Sea $(500 \mathrm{~m})$. Observed biomass increased with body size as a power law at FG (scaling exponent, $b=0.16$ ) and FSC $(b=0.32)$, but less convincingly at OM $(b=0.12$ but not significantly different from 0 ). A simple model was constructed to represent the same 16 metazoan size classes used for the observed spectra, all reliant on a common detrital food pool, and allowing the three key processes of ingestion, respiration and mortality to scale with body size. A micro-genetic algorithm was used to fit the model to observations at the sites. The model accurately reproduces the observed scaling without needing to include the effects of local influences such as hypoxia. Our results suggest that the size-scaling of mortality and ingestion are dominant factors determining the distribution of biomass across the meio- to macrofaunal size range in contrasting marine sediment communities. Both the observations and the model results are broadly in agreement with the "metabolic theory of ecology" in predicting a quarter power scaling of biomass across geometric body size classes.
\end{abstract}

\section{Introduction}

Marine sediments are sites of long-term removal, via burial, of organic carbon derived from productivity at the ocean surface and so play a key role in global biogeochemical cycles. The amount of organic carbon that is buried is determined by the rate of processing by benthic organisms with the majority of the settling carbon (the POC flux) respired back to the water column (Pfannkuche et al., 1999). A smaller fraction of the POC flux is incorporated into benthic biomass and the remainder is buried.

A major challenge to understanding benthic ecology and carbon flow, especially in the deep sea, is appropriate characterization of both community composition and its underlying dynamics. There now exists, however, a large volume of body-size-based research suggesting that it may not be necessary to resort to characterizing food web complexity and differences in functional groups in order to determine energy flow in ecological communities (e.g. Dickie et al., 1987). Allometry, the relation of body size to biological processes, provides an attractive alternative approach for meeting this challenge. First, body size can be easily measured and so enables direct comparison of different benthic habitats regardless of taxonomic makeup. Second, body size is an attribute of individual organisms that is closely coupled to key biological processes such as metabolism, as well as to community parameters such as biomass and abundance (e.g. Schmidt-Nielsen, 1984; Hildrew et al., 2007). The advent of the metabolic theory of ecology (MTE, Brown et al., 2004) has raised much interest in and debate of the body-size (allometric) approach among ecologists (e.g. Glazier, 2005; Hildrew et al., 2007) while allometric relations have provided many useful ecological insights into terrestrial and aquatic 
environments (Schmidt-Nielsen, 1984; Hildrew et al., 2007). Consequently, the body-size approach may prove useful in studies of benthic communities in both shallow (Blanchard et al., 2009) and deep-sea environments.

The biomass distributions of marine benthic communities were first studied using a size-based approach by Schwinghamer (1981). He constructed benthic biomass size spectra (BBSS) from six intertidal stations in the Northwest Atlantic and found a "characteristic" trimodal size spectrum (with biomass peaks in the size ranges $0.5-1 \mu \mathrm{m}, 64-125 \mu \mathrm{m}$ and $>2 \mathrm{~mm}$; corresponding to micro-, meio- and macrofauna, respectively) which was supported by later works (Schwinghamer, 1983, 1985). In contrast, other studies, primarily in shallow-water locations (Strayer, 1986; Drgas et al., 1998; Duplisea, 2000), found biomass increases that were continuous with increasing body size, suggesting that discontinuities in biomass distributions could be a result of sampling artefacts (Bett, 2013).

The pioneering work in modelling benthic community biomass distributions was undertaken by Peters (1983). Organisms within the community were assigned to one of five size classes that all fed from the same detritus food pool, and which were parameterized according to four body-sizebased processes: ingestion, respiration, egestion and mortality. Peters (1983) applied his model to study pesticide bioaccumulation and showed qualitative similarities with observations reported in the literature (Griesbach et al., 1982). More recently, Rakocinski (2009) applied Peters' model to investigate hypoxia in subtidal macrofauna. Other biomass size-based approaches have been used to model fisheries impacts on shelf benthic ecosystems (e.g. Blanchard et al., 2009).

Here, we first investigate the biomass size spectra of benthic metazoans $(1 \mu \mathrm{g}-32 \mathrm{mg})$ from three contrasting environments: the Northeast Atlantic (Faroe-Shetland Channel FSC, $1600 \mathrm{~m}$ ), the North Sea (Fladen Ground - FG, 150 m) and the Arabian Sea (Oman Margin - OM, $500 \mathrm{~m}$ ). The factors that control the distribution of biomass are then examined using a model that builds on the allometric approach of Peters (1983). To the best of our knowledge, this work is the first application of a numerical model based on allometry to the study of biomass distributions in varied marine benthic environments, especially the deep sea. In particular we explore whether a simple allometric model can represent strongly contrasting systems without recourse to invoking specific functional groups or local environmental influences. Our approach contrasts with other benthic modelling efforts, which have focused on elemental flows within sea bed communities (van Oevelen et al., 2006a, b)

\section{Methods}

\subsection{Field observations - sample collection and processing}

For practical reasons our field study focuses on a restricted size range of metazoans. In total the marine invertebrates may span a range of body lengths from $50 \mu \mathrm{m}$ (e.g. smallest nematodes) to $50 \mathrm{~cm}$ (e.g. large sea cucumbers), some 4 orders of magnitude; their corresponding body weights range over $5 \mathrm{ng}-5 \mathrm{~kg}$ wet weight, 12 orders of magnitude. The largest of the invertebrates (megabenthos) can only be physically sampled effectively by trawls and similar devices which only provide semi-quantitative data at best and their efficiency of collecting specimens is distinctly body-size related (Bett, 2001). The smallest invertebrates also pose considerable difficulties for quantitative study both in terms of their practical handling and visualization and in their separation from sedimentary and detrital particles. We have therefore concentrated on intermediate-sized invertebrates, the meioand macro-benthos (Table 2), which can be reliably, quantitatively sampled and readily extracted from sediment samples (Gage and Bett, 2005).

Samples were collected from three contrasting locations in 2000 and 2002: (i) a temperate shelf sea site in the Fladen Ground (FG), North Sea, (ii) an "Arctic" deep-water site in the Faroe-Shetland Channel (FSC), and (iii) a tropical midslope oxygen minimum zone site on the Oman Margin (OM), Arabian Sea. Site locations are illustrated in Fig. 1 and basic station data and environmental characteristics for each site are given in Table 1, together with estimates of particulate organic carbon flux to the seabed following the method of Lutz et al. (2007).

The Fladen Ground sampling site lies in the deeper part of the North Sea at the centre of a gyre with bottom water currents which are thought to be slight $\left(<0.25 \mathrm{~m} \mathrm{~s}^{-1}\right.$; de Wilde et al., 1986). Fladen Ground is thermally stratified during the summer months when the thermocline can be found between 30 and $70 \mathrm{~m}$. The annual variation in the bottom water temperature is small $\left(6-8^{\circ} \mathrm{C}\right.$, de Wilde et al., 1986).

The sampling site in the FSC lies between the Scottish Continental Shelf and the Faroe Plateau. It is representative of a cold $\left(<0^{\circ} \mathrm{C}\right.$, Turrell et al., 1999), pristine deep-water habitat at $1600 \mathrm{~m}$ depth.

The Arabian Sea sampling site $(\mathrm{OM})$ is characterized by a well-developed oxygen minimum zone (OMZ) that extends from about 100 to $1000 \mathrm{~m}$ water depth. The samples were collected from the core of the OMZ $(500 \mathrm{~m})$ where the benthic communities are subjected to hypoxic conditions (Billett et al., 2006).

At each location, five replicate samples were collected for large $(500 \mu \mathrm{m}$ sieve mesh) and small $(250 \mu \mathrm{m})$ macrobenthos, meiobenthos $(45 \mu \mathrm{m})$ and an intermediate-sized "mesobenthos" $(180 \mu \mathrm{m})$ using a Bowers and Connelly Megacorer (Gage and Bett, 2005). The Megacorer carries up to twelve 
Table 1. Station data and environmental characteristics of the three study sites including particulate organic carbon (POC) flux to the seabed estimated following Lutz et al. (2007).

\begin{tabular}{lccc}
\hline & Faroe-Shetland Channel & Fladen Ground & Oman Margin \\
\hline Date of sampling & 2 Sep 2000 & 11 Sep 2000 & 9 Dec 2002 \\
Station(s) sampled (unique identifier) & 55447 & $55526 / 7 / 8$ & $55754 / 64$ \\
Water depth (m) & 1623 & 153 & 507 \\
Sampling position & $61^{\circ} 55.0^{\prime} \mathrm{N}$ & $58^{\circ} 16.0^{\prime} \mathrm{N}$ & $23^{\circ} 23.0^{\prime} \mathrm{N}$ \\
& $002^{\circ} 48.1^{\prime} \mathrm{W}$ & $000^{\circ} 52.6^{\prime} \mathrm{E}$ & $059^{\circ} 00.0^{\prime} \mathrm{E}$ \\
Bottom water temperature $\left({ }^{\circ} \mathrm{C}\right)$ & -1 & 8 & 13 \\
Sediment mud content $($ particles $<63 \mu \mathrm{m}, \%)$ & $>80$ & $>80$ & $>75$ \\
Bottom water oxygen concentration $\left(\mathrm{mLL}^{-1}\right)$ & 6 & 6 & 0.1 \\
POC flux to seabed $\left(\mathrm{g} \mathrm{C} \mathrm{m}^{-2} \mathrm{yr}^{-1}\right)$ & 14.5 & 42.6 & 8.8 \\
\hline
\end{tabular}

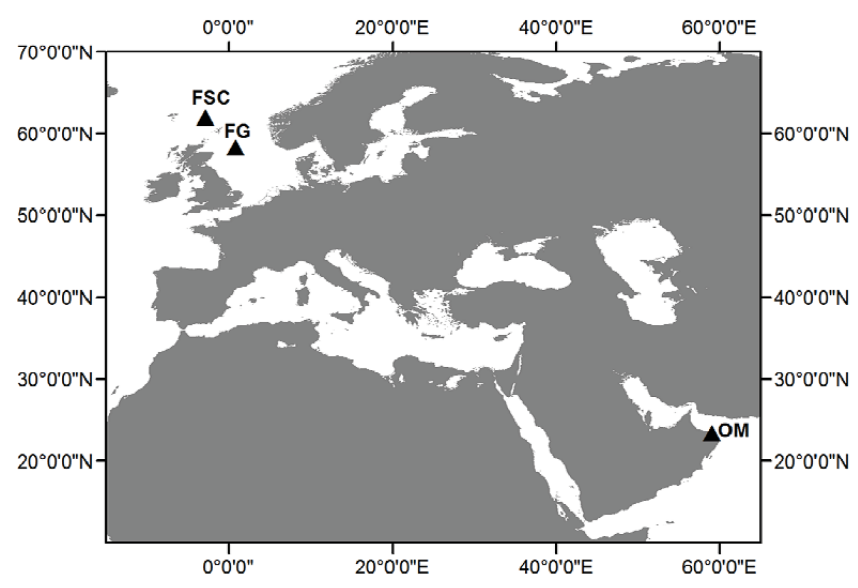

Figure 1. Chart showing the locations of the three study sites: Fladen Ground (FG), Faroe-Shetland Channel (FSC), and Oman Margin (OM).

$10 \mathrm{~cm}$ diameter core tubes: eight cores $\left(628 \mathrm{~cm}^{2}\right)$ were collected for a large macrobenthos sample, four cores $\left(314 \mathrm{~cm}^{2}\right)$ for small macrobenthos, one core $\left(78.5 \mathrm{~cm}^{2}\right)$ for mesobenthos, and a $10 \mathrm{~cm}^{2}$ subsample from a single core for a meiobenthos sample. Macro- and mesobenthos samples were of the $0-10 \mathrm{~cm}$ sediment horizon, the meiobenthos sample was of the $0-5 \mathrm{~cm}$ horizon. All samples were preserved in Borax-buffered $10 \%$ formalin shortly after collection.

The fauna of macro- and mesobenthos samples were separated by wet sieving; the fauna of meiobenthos samples were extracted by differential floatation in colloidal silica (Ludox, specific gravity of 1.15 ; Kaariainen, 2006). The total metazoan fauna of the macrobenthos and meiobenthos samples was enumerated and identified to major taxon. In the case of the mesobenthos samples, a random subsample of the metazoan fauna was enumerated and identified to major taxon. Subsampling was undertaken with a "Jensen sample splitter" (Kaariainen, 2006).
Individual body weights were determined as the product of biovolume and a specific gravity of 1.13 (Kaariainen, 2006). Body volume was estimated by dividing the morphology into a number of geometric shapes (e.g. cones, cylinders, truncated cones) and making the measurements necessary to calculate the volume of each. For each primary sieve fraction (i.e. $500,250,180$ and $45 \mu \mathrm{m}$ ) the body weight of every metazoan was calculated except where more than 150 specimens of a particular taxon were present, in which case a subsample of 100 specimens were selected at random from a gridded petri dish.

The abundance of benthic invertebrates is expected to decline logarithmically with body size (Peters, 1983) such that the upper end of the body-size range likely to be encountered will depend on the physical size of the sampling unit. As the abundance of the largest specimens per sampling unit approaches unity, the resultant data will become erratic with a high variance. Consequently we have set an upper bodysize limit (39.1 mg wet weight) in the following analyses, above which we believe the data lack sufficient precision. The lower body-size limit is notionally set by the minimum sieve mesh size employed $(45 \mu \mathrm{m})$ to extract invertebrates from the sediment samples. The variable body forms, protruding appendages and adherent debris of individual specimens all act, however, to blur this lower boundary (see Bett, 2013). Again, a lower limit was set $(0.6 \mu \mathrm{g}$ wet weight), below which we believe specimens were not efficiently sampled in the present study. In total, this yields 16 size classes (5-20) on the X2 geometric scale of Warwick (1984) in which each size class is twice that of the adjacent class below.

In the subsequent analyses, only size classes 5-20 have been included, on the basis that they represent the reliably sampled portion of the total size range encountered (see above). Replicate size spectra data were summarized to geometric mean and $95 \%$ confidence intervals following logarithmic transformation. $\mathrm{A} \log (x+1)$ transformation was employed in the case of abundance data and a $\log \left(x+\mathrm{wt}_{i}\right)$ in the case of biomass data, where $\mathrm{wt}_{i}$ is the nominal weight of a single individual in size class $i$. For nominal weight we 


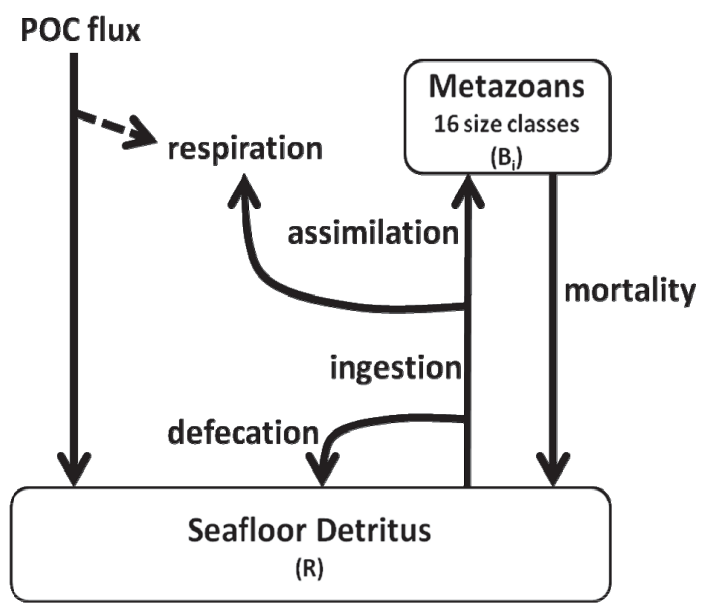

Figure 2. Flow diagram of model structure. The solid lines represent processes explicitly represented in the model.

follow Blanco et al. (1998):

$\mathrm{wt}_{i}=\mathrm{wt}_{1}\left(\frac{c^{b+1}-1}{(c-1)(b-1)}\right)^{\frac{1}{b}}$

where $\mathrm{wt}_{1}$ is the lower weight limit of the size class (see Table 2, and Warwick, 1984), $c$ is the ratio of geometric increase (i.e. 2), and $b$ is the slope of the abundance-size spectrum (uniformly set to -0.7 , for consistency and repeatability of the method). Geometric mean abundance and biomass data were then log transformed and regressed on log-transformed nominal size class weights (simple least squares regression, implemented using Minitab 15, Minitab Inc.). Regression slopes were compared to standard allometric ratios (e.g. $1 / 3,1 / 4)$ using a $t$ test.

\subsection{Model structure}

The model is designed to be as simple as possible while retaining the ability to vary physiological rates as a function of organism size. It is therefore intended as a minimal model to capture the first-order behaviour of the observed biomass spectra. The model incorporates 16 metazoan size classes feeding on a single food pool that originates from the supply of particulate organic carbon (POC) from the water column above (Fig. 2). The number of model size classes is derived directly from our measurements and defined by a $\mathrm{X} 2$ geometric scale with mean body sizes $\left(W_{i}\right)$ ranging from $8.9 \times 10^{-7}$ to $2.9 \times 10^{-2} \mathrm{~g}$ wet weight (Table 2). Each metazoan size class undertakes ingestion, defecation, assimilation of ingested substrates, respiration, growth and mortality. The size classes do not directly interact. In effect, competitive interactions are reduced to simple body size scaling of ingestion, respiration and mortality. Similarly, predation is not explicitly included but may effectively occur via the common food pool, i.e. all mortality returns to the food pool and may be re-used by any size class.
Table 2. Geometric body size classes used in this study (adapted from Warwick, 1984).

\begin{tabular}{cccc}
\hline $\begin{array}{c}\text { Size } \\
\text { class }\end{array}$ & $\begin{array}{c}\text { Size range } \\
\text { (g wwt) }\end{array}$ & $\begin{array}{c}\text { Geometric } \\
\text { mean } \\
\text { weight } \\
\text { (g wwt) }\end{array}$ & $\begin{array}{c}\text { Approximate } \\
\text { wet } \\
\text { weight }\end{array}$ \\
\hline 5 & $6.0 \times 10^{-7}$ to $1.2 \times 10^{-6}$ & $8.4 \times 10^{-7}$ & $1 \mu \mathrm{g}$ \\
6 & $1.2 \times 10^{-6}$ to $2.4 \times 10^{-6}$ & $1.7 \times 10^{-6}$ & $2 \mu \mathrm{g}$ \\
7 & $2.4 \times 10^{-6}$ to $4.8 \times 10^{-6}$ & $3.4 \times 10^{-6}$ & $3 \mu \mathrm{g}$ \\
8 & $4.8 \times 10^{-6}$ to $9.5 \times 10^{-6}$ & $6.7 \times 10^{-6}$ & $7 \mu \mathrm{g}$ \\
9 & $9.5 \times 10^{-6}$ to $1.9 \times 10^{-5}$ & $1.3 \times 10^{-5}$ & $13 \mu \mathrm{g}$ \\
10 & $1.9 \times 10^{-5}$ to $3.8 \times 10^{-5}$ & $2.7 \times 10^{-5}$ & $27 \mu \mathrm{g}$ \\
11 & $3.8 \times 10^{-5}$ to $7.6 \times 10^{-5}$ & $5.4 \times 10^{-5}$ & $54 \mu \mathrm{g}$ \\
12 & $7.6 \times 10^{-5}$ to $1.5 \times 10^{-4}$ & $1.1 \times 10^{-4}$ & $108 \mu \mathrm{g}$ \\
13 & $1.5 \times 10^{-4}$ to $3.1 \times 10^{-4}$ & $2.2 \times 10^{-4}$ & $216 \mu \mathrm{g}$ \\
14 & $3.1 \times 10^{-4}$ to $6.1 \times 10^{-4}$ & $4.3 \times 10^{-4}$ & $432 \mu \mathrm{g}$ \\
15 & $6.1 \times 10^{-4}$ to $1.2 \times 10^{-3}$ & $8.6 \times 10^{-4}$ & $1 \mathrm{mg}$ \\
16 & $1.2 \times 10^{-3}$ to $2.4 \times 10^{-3}$ & $1.7 \times 10^{-3}$ & $2 \mathrm{mg}$ \\
17 & $2.4 \times 10^{-3}$ to $4.9 \times 10^{-3}$ & $3.5 \times 10^{-3}$ & $3 \mathrm{mg}$ \\
18 & $4.9 \times 10^{-3}$ to $9.8 \times 10^{-3}$ & $6.9 \times 10^{-3}$ & $7 \mathrm{mg}$ \\
19 & $9.8 \times 10^{-3}$ to $2.0 \times 10^{-2}$ & $1.4 \times 10^{-2}$ & $14 \mathrm{mg}$ \\
20 & $2.0 \times 10^{-2}$ to $3.9 \times 10^{-2}$ & $2.8 \times 10^{-2}$ & $28 \mathrm{mg}$ \\
\hline
\end{tabular}

In terms of the total benthic ecosystem, the incoming POC flux has to support the consumption of organisms of smaller and larger body sizes than are included in our modelled range (the meio- and macro-benthos). The larger forms include the megabenthos and demersal fish; the smaller forms, the "bacteria" (prokaryotes) and small eukaryotes (e.g. foraminiferans). There are practical reasons to exclude foraminiferans from the model; the full range of foraminiferal entities in our size range can only be recognized by a few people worldwide, live specimens are difficult to distinguish from the dead, and the volume of live protoplasm (and hence body mass) is difficult to estimate reliably. We do however recognize their importance (see e.g. Bett, 2014) and are currently actively pursuing a reliable means of foram body mass estimation. At the physical scale of sediment core samples (ca. 20-100 $\mathrm{cm}^{2}$ ) bacteria dominate the consumption of POC (e.g. Pfannkuche et al., 1999). We model this additional consumption by rescaling the incoming POC flux to that proportion available to the meio- and macro-benthos. We refer to the proportion consumed by other size classes as $f_{\text {other }}$ to acknowledge the dominance of bacterial respiration at small physical scales and the respiration of organisms larger than our model considers. 
The model equations are given below. Model biomass units are expressed in $\mathrm{g}$ wet weight per $\mathrm{m}^{2}\left(\mathrm{gwwt} \mathrm{m}^{-2}\right)$ and fluxes given as yearly values $\left(\mathrm{g} \mathrm{wwt} \mathrm{m}^{-2} \mathrm{yr}^{-1}\right)$. The rate of change of metazoan biomass, $B_{i}$, in each size class $i$ is given by

$$
\frac{\mathrm{d} B_{i}}{\mathrm{~d} t}=\underbrace{\underbrace{\alpha I_{i}}_{\text {assimilation }}-\underbrace{r_{i} \alpha I_{i}}_{\text {respiration }}}_{\text {net production }}-\underbrace{m_{i} B_{i}^{2}}_{\text {mortality }},
$$

where $\alpha$ is the assimilation efficiency, $r_{i}$ is the respiration coefficient expressed as a fraction of assimilation, $m_{i}$ is a coefficient for metazoan mortality rate and $I_{i}$ is the ingestion rate for size class $i$, taken here to be

$I_{i}=g_{i} R B_{i}$

where $R$ is the stock of detritus and the ingestion coefficient $g_{i}$ can vary allometrically (see Table 3 ). The subscript $i$ (ranging 5-20) indicates that a property or parameter can be body-size dependent.

Net metazoan production (i.e. growth) is calculated as the difference between rates of assimilation and respiration (Eq. 1), representing a departure from Peter's (1983) model which has an explicit body-size-dependent growth term. For simplicity, rates of assimilation are taken to be a constant (assimilation efficiency, $\alpha$ ) fraction of ingestion (Eq. 2). Respiration rates are taken to be a fraction of assimilation $\left(r_{i}\right)$ lost to the respiratory pathway. Note that in our model $\alpha$ takes a single value whereas $r_{i}$ varies with size class. Our approach is similar to contemporary pelagic ecosystem models (e.g. Anderson and Pondaven, 2003) in which parameters such as assimilation and growth efficiencies are assigned to specify the fate of material ingested by consumers.

The loss terms for each size class are defecation (the fraction of ingestion not assimilated), mortality and respiration. Losses through defecation and mortality are returned to the food pool, $R$ (Eq. 3), while respiration across the size classes balances the POC flux at steady state.

Simple first-order reaction functions are used to model both ingestion (Eq. 2) and mortality (Eq. 1). Hence, specific rates of ingestion and mortality are regulated by the concentration of the food source and biomass, respectively, yielding a density-dependent formulation in the case of mortality, as in, for example, Benoit and Rochet (2004). Use of density-dependent terms, through either resource-limited growth or mortality, is an established way of preventing competitive exclusion in model systems (Brown, 1989; Chesson, 2000). Here, a stable solution with co-existence of the 16 size classes was not found when using a linear mortality term. We choose to use a quadratic, density-dependent term rather than a Michaelis-Menten formulation purely out of parsimony, as the latter would involve an extra parameter. Although data are currently lacking to provide explicit support for such density dependence in the benthic realm, density-dependent mortality is a recognized mechanism for regulating natural populations of pelagic organisms (Ohman and Hirche, 2001; Minto et al., 2008).

The rate of change of the organic matter available for ingestion, the detrital food pool, $R$, is taken to be

$$
\begin{aligned}
\frac{\mathrm{d} R}{\mathrm{~d} t} & =\left(1-f_{\text {other }}\right) \text { POC }_{\text {flux }} \\
& +\underbrace{\sum_{i=5}^{i=20}(1-\alpha) I_{i}}_{\text {defecation }}+\underbrace{\sum_{i=5}^{i=20} m_{i} B_{i}^{2}}_{\text {mortality }}-\underbrace{\sum_{i=5}^{i=5} I_{i}}_{\text {ingestion }},
\end{aligned}
$$

where $\mathrm{POC}_{\text {flux }}$ is the flux of organic carbon to the seabed. The role of bacteria and Foraminifera (and organisms larger than class 20) is represented in the food pool, Eq. (3), through the parameter $f_{\text {other }}$, the fraction of the POC flux that is respired by these components of the benthic community (i.e. the fraction not reaching the metazoan meio- and macrobenthos). Note that $\mathrm{POC}_{\text {flux }}$ and $f_{\text {other }}$ only ever occur in the model equations together and so cannot be determined independently by the optimization procedure described later. For this reason, we define a new parameter

$Q=\left(1-f_{\text {other }}\right) \mathrm{POC}_{\text {flux }}$,

which represents the POC flux available to the modelled community. This will of course be smaller than the total flux, $\mathrm{POC}_{\text {flux }}$. For the model, $Q$ is converted to units of $\mathrm{gC} \mathrm{m}^{-2}$ for comparison to observations by multiplying by 0.077 , which is a product of the factors for converting wet weight to dry weight $(0.22)$ and dry weight to carbon $(0.36)$ (Brey et al., 2010).

The model equations do not describe a system in which growth gives rise to the explicit transfer of individuals in size class $i$ to size class $i+1$. This is because the "currency" of the model is biomass; for each size class processes occur at a rate controlled by the amount of biomass in that size class, not the number and/or weight of individuals.

The few available studies suggest that temporal variability in benthic biomass size spectra appears to be minimal (Schwinghamer, 1981, 1983, 1985; Drgas et al., 1998; Duplisea et al., 2000) thus we consider only steady-state solutions of the model. At steady state, total respiration across all the size classes equals the $\left(1-f_{\text {other }}\right)$ fraction of incoming POC flux.

\subsection{Model parameterization}

We base the model on an allometric approach, with three parameters $g_{i}, m_{i}$ and $r_{i}$ assumed to follow a power law scaling with body size:

$\operatorname{par}_{i}=a W_{i}^{b}$,

where $\operatorname{par}_{i}$ is the value of the parameter for the $i$ th size class and $W_{i}$ is the size of organisms in class $i$. For each parameter 


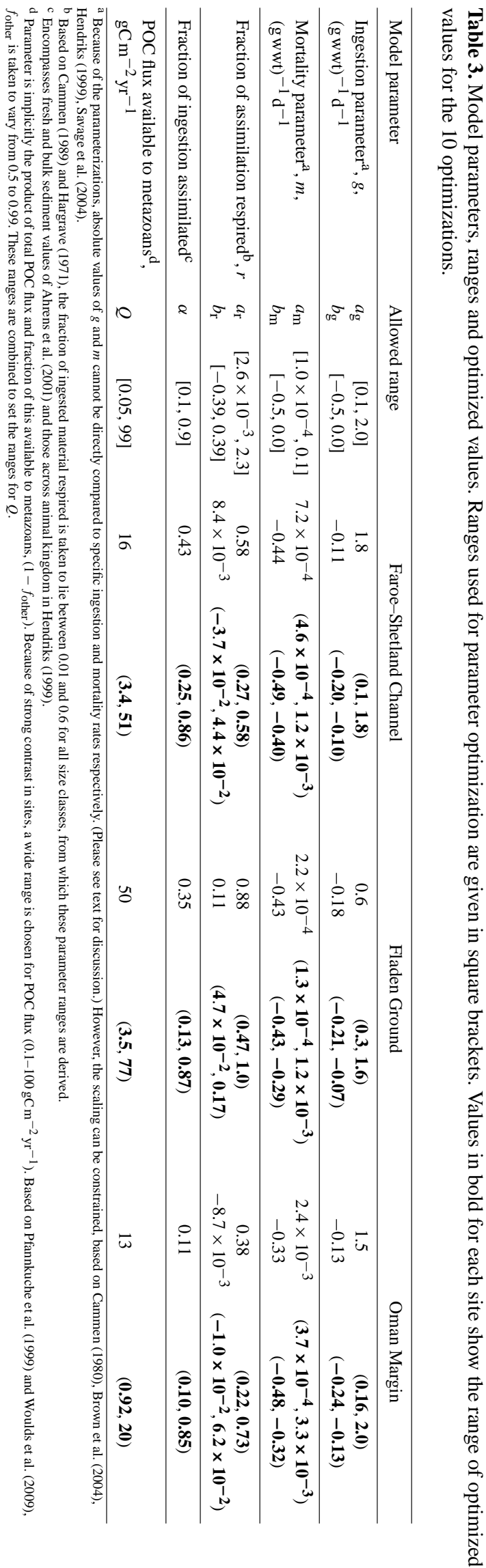

the prefactor, $a$, and scaling exponent, $b$, can be estimated by comparison of model output to size spectrum data, as described in the next section.

For the ingestion parameter $\left(g_{i}\right)$ the above power law form mimics the observations of Cammen (1980) showing a power law relationship between organic carbon ingestion rate and body size of benthic deposit feeders and detritivores. A sizebased approach to mortality follows studies in both aquatic (Savage et al., 2004) and non-aquatic (Hendriks, 1999) organisms, though natural mortality rates for benthic organisms are difficult to parameterize because of scarcity of relevant experimental data.

Constraints are placed upon the model parameters in two ways. First, for $g$ and $m$, there is previous work to directly constrain the prefactor and scaling exponent (Table 3). For this reason, ranges for the prefactor and scaling exponent are prescribed for both of these parameters from which the optimizer can choose values. Second, for the remaining allometrically scaling parameter, $r$, the prefactor and scaling exponent cannot be constrained directly but it is possible to put some constraints on the value the parameter can take for the smallest and largest size classes. These values are then used to calculate the scaling exponent and prefactor from which it can derive the parameter value for the other size classes. For all three processes which are allowed to scale with body size (ingestion, respiration and mortality) the range of allowed parameter values includes zero for the scaling exponent so that all can choose to have a process that does not scale with body size if it gives a better fit to the data. Hence, the results are not biased in favour of an allometric solution. Furthermore, to reflect the uncertainty regarding allometric behaviour in respiration, the same range of parameter values for $r_{i}$ is used for smallest and largest size classes so that the relationship to body-size can be either increasing or decreasing (i.e. positive or negative scaling exponent). In summary, the relationship to body size emerges from optimizing the model to give the best reproduction of the observations.

\subsection{Model parameter optimization}

The model was fitted to the full data set, in which all replicates were used to enable the most robust fit possible in this study. The fitting was achieved using the micro-genetic algorithm found in Ward et al. (2010). A brief summary is presented here. For each parameter, a range of allowed values is chosen based on previous observations wherever possible (Table 3). With one exception, the range for each parameter is then divided to give $64\left(=2^{6}\right)$ equally spaced values between the allowed lower and upper limit inclusive. For the mortality prefactor, because the allowed range spans several orders of magnitude the range is divided logarithmically so as not to bias the result towards a higher parameter value. Discretizing the parameter ranges allows each value to be encoded by a 6-bit binary number. The 6-bit binary representations of each parameter value are then stitched together to 
give a 48-digit binary number (as there are eight parameters in the model), referred to as the "genotype" corresponding to this parameter set. Initially, the optimizer randomly generates eight genotypes; the rule of thumb is that the number of genotypes should match the number of parameters. The model is run independently using the parameter set corresponding to each genotype. A "cost" is then calculated for each parameter set compared to the data, calculated as the simple sum of square differences between log-transformed observation and model output for each size class. As there are five observations for each size class, each size class contributes five terms to the sum. The genotype corresponding to the lowest cost is automatically passed intact to the next "generation". To generate the other seven genotypes necessary for the next generation, pairs of the eight genotypes from the current generation are combined. Each of the pairs used to make a genotype for the next generation is chosen at random - with probability proportional to the reciprocal of their cost - so those with lowest costs are most likely to be chosen. Once a pair have been chosen, a random integer between 2 and 47 is chosen and the two genotypes are combined at this location e.g. if the combination location is 34 , the new genotype has the first 33 elements of the binary genotype of parent 1 and the last 15 elements of parent 2 . Once a new set of eight genotypes has been created, the process repeats.

The optimizer is run through 5000 generations. Typically there is little change to the optimal solution after 2000 generations. As a further precaution against getting caught in local minima of the cost function, the whole process is repeated 10 times using different sets of initial genotypes. The best fit (i.e. the lowest cost function of the 10 repeats) is presented for each site. Because of difficulties involved in handling zeroes when log-transforming to calculate the cost function, zero values were removed. As a check, the optimization was repeated using data with zeros replaced by mean values for that biomass interval and similar results were obtained.

Two additional criteria, taken from the literature, were imposed in determining the passing of genotypes to the next generation in the optimization procedure: (1) that the annual ratio of net production (assimilation minus respiration) to biomass (effectively a specific net growth rate) decreases with body size (e.g. Banse and Mosher, 1980) with a value falling between 0.1 and $2.0 \mathrm{yr}^{-1}$ for the largest (macrofaunal) class and a value falling between 4 and $7 \mathrm{yr}^{-1}$ for the smallest (meiofauna) size class (Schwinghamer et al., 1986); and (2) that individual respiration rates increase with body size (e.g. Peters, 1983).

\section{Results}

\subsection{Observed size spectra: abundance and biomass}

Abundances decreased with size at all sites. Biomass increased with size at two sites but the trend was not signifi-
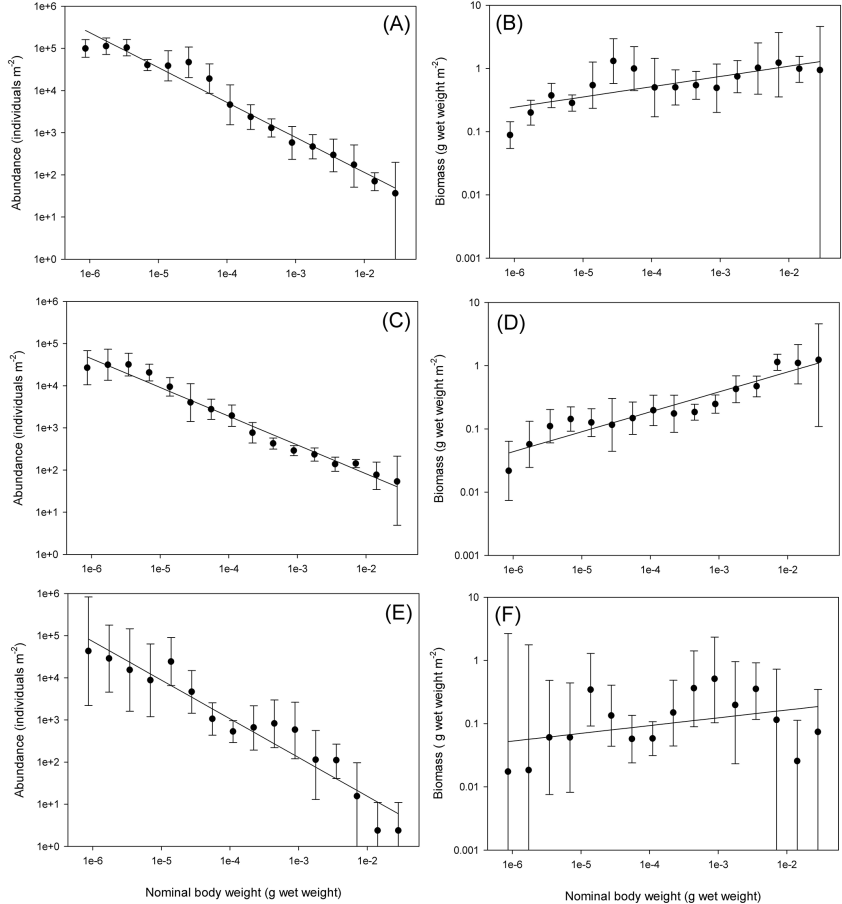

Figure 3. Abundance and biomass spectra for Fladen Ground $(\mathbf{a}, \mathbf{b})$, Faroe-Shetland Channel (c, d) and Oman Margin (e, f). Geometric mean (points) and $95 \%$ confidence intervals (bars) based on five replicate samples are shown together with regression lines for the geometric mean data.

cant given the variability in the data at the third site (Fig. 3). We focus on this first-order phenomenon of the decrease (increase) in abundance (biomass). Recent work (Bett, 2013, 2014; Warwick, 2014) discusses the extent to which variability about the trend is likely to be a robust signal or a result of sampling artefacts.

The abundance-body-size relationships were all statistically significant with scaling exponents (and standard error) of $-0.83(0.04),-0.68(0.03)$ and $-0.92(0.07)$ at FG FSC and OM, respectively (Table 4). The scaling exponent at FG was not significantly different from $-3 / 4$, in line with metabolic theory (Brown et al., 2004), whereas at FSC the scaling was not significantly different from $-2 / 3$, in line with surface area: volume theory (Schmidt-Nielsen, 1984). OM had the steepest abundance-body-size slope, consistent with other studies of hypoxic environments (Chapelle and Peck, 1999; Quiroga et al., 2005). The latter suggests that the steeper slopes may be due to smaller bodied organisms being better adapted to hypoxic conditions (Gooday et al., 2010).

Total abundance (in classes 5-20) was lowest at FSC $\left(1.51 \times 10^{5}\right.$ ind. $\mathrm{m}^{-2}, 95 \%$ CI: $0.96-2.19 \times 10^{5}$ ind. $\left.\mathrm{m}^{-2}\right)$, almost twice as high at $\mathrm{OM}\left(2.82 \times 10^{5}\right.$ ind. $\mathrm{m}^{-2}, 95 \% \mathrm{CI}$ : $0.26-9.39 \times 10^{5}$ ind. $\mathrm{m}^{-2}$ ), and over three times higher at FG $\left(5.11 \times 10^{5}\right.$ ind. $\mathrm{m}^{-2}, 95 \%$ CI: $3.28-7.31 \times 10^{5}$ ind. $\left.\mathrm{m}^{-2}\right)$. At all sites, meiofauna contributed most to the total abundance 
Table 4. Summary of regression analyses for abundance and biomass relationships with nominal body weight for three study sites (FG, Fladen Ground; FSC, Faroe-Shetland Channel; OM, Oman Margin) assuming a relationship parameter $=a W^{b}$. ANOVA probability $(p)$, coefficient of determination $\left(R^{2}\right)$, prefactor $(a)$, scaling $(b)$, standard error for $b$ and its $t$-test comparison probabilities $(p)$ with standard allometric ratios are shown.

\begin{tabular}{|c|c|c|c|c|c|c|c|c|c|c|c|}
\hline \multirow[t]{2}{*}{ Parameter } & \multirow[t]{2}{*}{ Site } & \multirow[t]{2}{*}{$a$} & \multirow[t]{2}{*}{$b$} & \multirow[t]{2}{*}{$b$ s.e. } & \multirow[t]{2}{*}{ ANOVA $(p)$} & \multirow[t]{2}{*}{$R^{2}(\%)$} & \multicolumn{5}{|c|}{ Slope comparisons ( $t$ test, $p$ ) } \\
\hline & & & & & & & $1 / 3$ & $1 / 4$ & 0 & $-2 / 3$ & $-3 / 4$ \\
\hline \multirow[t]{3}{*}{ Abundance } & FSC & 0.55 & -0.68 & 0.03 & $<0.001$ & 97.5 & $<0.00001$ & $<0.00001$ & $<0.00001$ & $\mathrm{~ns}$ & $<0.05$ \\
\hline & FG & 0.40 & -0.83 & 0.04 & $<0.001$ & 96.7 & $<0.00001$ & $<0.00001$ & $<0.00001$ & $<0.002$ & $\mathrm{~ns}$ \\
\hline & $\mathrm{OM}$ & -0.65 & -0.92 & 0.07 & $<0.001$ & 91.9 & $<0.00001$ & $<0.00001$ & $<0.00001$ & $<0.005$ & $<0.05$ \\
\hline \multirow[t]{3}{*}{ Biomass } & FSC & 0.53 & 0.31 & 0.03 & $<0.001$ & 88.6 & $\mathrm{~ns}$ & $<0.05$ & $<0.00001$ & $<0.00001$ & $<0.00001$ \\
\hline & FG & 0.36 & 0.16 & 0.04 & 0.001 & 51.5 & $<0.001$ & $<0.05$ & $<0.005$ & $<0.00001$ & $<0.00001$ \\
\hline & $\mathrm{OM}$ & -0.54 & 0.12 & 0.08 & $\mathrm{~ns}$ & 8.4 & $<0.05$ & $\mathrm{~ns}$ & ns & $<0.00001$ & $<0.00001$ \\
\hline
\end{tabular}

(84-99\%), with mesofauna and macrofauna far less abundant. The exception was at FG where mesofauna (molluscs, mostly Veneroidae and Philinidae) accounted for over $15 \%$ of the total, most likely representing a recent recruitment event. Nematodes dominated the meiofaunal size range (> $90 \%$ ) and polychaetes (mostly Paraonidae, Capitellidae and Aricidae at FSC, Amphinomidae, Capitellidae and Nereidae dominating at FG and almost exclusively Ampharetidae at $\mathrm{OM}$ ) accounted for the majority ( $>60 \%$ ) of individuals in the macrofaunal size range at all sites. Molluscs (mostly Veneroidae and Philinidae) dominated the mesofauna at FG while no one group dominated the mesofaunal size classes at the other sites.

Increasing trends in biomass (Fig. 3) were statistically significant $(p \leq 0.001)$ at FSC and FG with scaling exponents (and standard errors) of $0.32(0.03)$ and $0.16(0.04)$, respectively (Table 4). In contrast, the increase in biomass with size was less convincing at $\mathrm{OM}$ (the scaling exponent of 0.12 with standard error 0.08 was not significantly different from zero or $-1 / 4)$.

Total mean biomass at FG $\left(12.1 \mathrm{gwwt} \mathrm{m}^{-2}, 95 \% \mathrm{CI}\right.$ : $\left.6.8-21 \mathrm{wwt} \mathrm{m}^{-2}\right)$ was approximately twice the value at the FSC site $\left(6.6\right.$ g wwt m$^{-2}, 95 \%$ CI: $\left.3.5-11.7 \mathrm{wwt} \mathrm{m}^{-2}\right)$ and more than three times higher than at $\mathrm{OM}\left(3.4 \mathrm{gwwt} \mathrm{m}^{-2}\right.$, $95 \%$ CI: $1.6-6.3 \mathrm{wwt} \mathrm{m}^{-2}$ ). Tukey simultaneous tests indicated that only the difference between FG and OM was statistically significant $(p<0.05)$.

Macrofauna (sensu stricto: i.e. $>500 \mu \mathrm{m}$ excluding taxa typically regarded as meiofaunal; Hessler and Jumars, 1974) accounted for most of the total biomass at all locations (92, 69 and $68 \%$ at FG, FSC and OM respectively), with polychaetes dominating this group. Mesofaunal biomass $(<$ $500 \mu \mathrm{m},>180 \mu \mathrm{m}$, excluding meiofaunal taxa) contributed less than $4 \%$ at the FSC and OM but $26 \%$ at FG. Polychaetes dominated the mesofaunal biomass at FG and OM, with no overall dominant group at FSC. The meiofauna ( $>45 \mu \mathrm{m}$, excluding macrofaunal taxa), dominated by nematodes, accounted for less than $7 \%$ of the total biomass at FG and FSC. At $\mathrm{OM}$, the proportion of meiofaunal biomass was more than four times greater $(28 \%)$ than at the other two sites, potentially reflecting the tolerance of nematodes to hypoxic conditions (e.g. Heip et al., 1985).

\subsection{Modelled biomass size spectra}

It should be noted that there is considerable variability in optimal parameter values across the 10 optimizations. This is a common feature when fitting models to data and indicates that the data available cannot constrain all processes in the model, as is invariably the case. For this reason the results need to be viewed with an awareness that for each of the three sites, while the best fit to data shown in Fig. 4 demonstrates how well the model can do, the results of the $10 \mathrm{op}-$ timizations look very similar and only have slightly different costs. Hence, undue weight should not be given to the specific values for the best optimization in Table 3. Consideration of the results needs to take the variability in optimized parameters (also shown in Table 3 ) into account. The biomass spectra produced by the model at each site are shown in Fig. 4, and the associated parameter values are shown in Table 3. In each case, both the best fit and the range of fits from the 10 optimizations are shown. As an equal number of data are available for all three sites, the costs associated with the model fit to each site can be directly compared. Defined as the one with lowest cost, the best fit among the sites is for the FSC, followed by the FG and then the OM. The total biomass modelled at each of FSC $\left(5.7 \mathrm{~g} \mathrm{wwt} \mathrm{m}^{-2}\right)$, FG $\left(10.8 \mathrm{~g} \mathrm{wwt} \mathrm{m}^{-2}\right)$ and $\mathrm{OM}\left(3.5 \mathrm{~g} \mathrm{wwt} \mathrm{m}^{-2}\right)$ is similar to measured values (see above). Model biomass increases with body size at all sites, and the model is seen to do a good job of reproducing the general trend in observations when compared to the empirical fit in Fig. 3. More quantitatively, the scaling of biomass produced by the best-fitting models for the FSC (0.32) and FG (0.18) agrees well with the empirical fit to observations described earlier $(0.32,0.16$ respectively see Table 5). The model does, however, differ in best model fit (0.20) and empirical (0.12) scaling at OM. Furthermore, for this location, the model scaling only varies between 0.19 and 0.21 across the 10 optimizations. However, the standard 

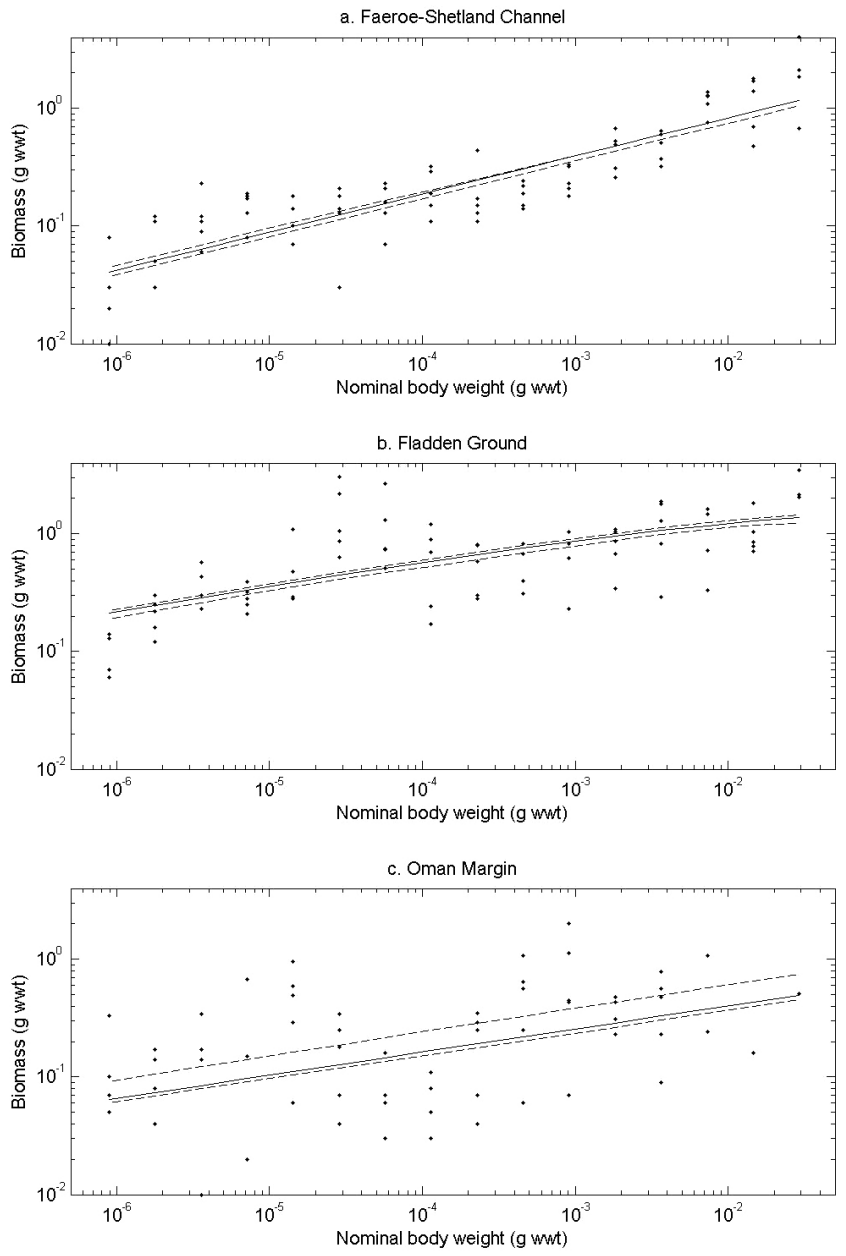

Figure 4. Optimized model biomass size spectra for each site. The observations contain five replicates per size class (closed circles). Dashed lines show the envelope for the 10 optimizations. The solid line corresponds to the optimization that resulted in the best fit to data.

error in the scalingestimated from observations (see Table 4) for $\mathrm{OM}(0.08)$ is considerably larger than that for either of FSC (0.03) and FG (0.04), reflecting the greater variability apparent even by eye in the data (Fig. 3). Consequently, even for OM the model is within the uncertainty associated with the scaling estimates.

\subsection{The allometry of model processes}

The model represents the biomass in each size class as a balance between the three processes of assimilation, respiration and mortality. As described earlier, each of these processes is allowed to scale independently with size via a single scaling parameter $\left(g_{i}, r_{i}\right.$ and $m_{i}$, respectively).

For assimilation, the structure of the model parameterization (see Eq. 2) means that the specific assimilation rate will scale in the same way as the parameter $g_{i}$. As the model further represents assimilation as a constant $(\alpha)$ fraction of ingestion, the scaling of $g_{i}$ also describes the behaviour of ingestion in the model. Empirical studies have advocated a $-1 / 4$ power law for mass-specific ingestion (e.g. Cammen, 1980; Savage et al., 2004). Although the scaling for the optimized runs has the same trend as this with size, the absolute values are systematically smaller than 0.25 (Table 3 ). Although the lower limit of the range of scaling for each of the three sites FSC ( -0.20 to -0.10$),$ FG $(-0.21$ to -0.07$)$ and $\mathrm{OM}(-0.24$ to -0.13$)$ is close to -0.25 , the value for the "best" optimization in each case (FSC, -0.11 ; FG, -0.18 ; $-0.13)$ corresponds to a weaker scaling with biomass.

For mortality, the scaling parameter, $m_{i}$, does not represent the specific mortality rate. Because of the form of the parameterization used in the model (Eq. 1), the specific mortality rate is given by $m_{i} B_{i}$. Hence, the scaling exponent of the specific mortality is the sum of the scaling exponents for $m_{i}$ and $B_{i}$, given in Table 5. For all three sites, there is a non-zero scaling, i.e. an allometric representation of mortality. Furthermore, in all cases the model-specific mortality decreases with size. This is, however, a consequence of the additional imposed criterion (see Sect. 2.4) that the specific net growth rate decrease with size, since at steady state the specific mortality rate has to equal the specific net growth rate for each size class. The same empirical studies already cited in the context of assimilation (Cammen, 1980; Savage et al., 2004) imply that specific mortality may scale as -0.25 . Support for this from the model is mixed (Table 5). For FG the best fit has a scaling of exactly -0.25 but the range extends from this value to -0.11 . For OM the range across the 10 optimizations $(-0.26,-0.12)$ encompasses -0.25 even if the best fit has a scaling of -0.13 . For FSC, however, not even the range $(-0.17,-0.09)$ includes -0.25 . Regarding particular values of the specific mortality rate, they are consistent across all three sites with values of $1.3-1.9 \times 10^{-2}$ day $^{-1}$ for the smallest size class and $1.0-5.3 \times 10^{-3} \mathrm{day}^{-1}$ for the largest. Across the three sites, particular values for the specific assimilation rate are consistently between $1.7 \times 10^{-2}$ and $3.9 \times 10^{-2} \mathrm{day}^{-1}$ for the smallest size class and between $2.2 \times 10^{-3}$ and $10.0 \times 10^{-3} \mathrm{day}^{-1}$ for the largest.

There is less evidence that the scaling of the fraction of assimilated material that is respired, $b_{\mathrm{r}}$, has a strong influence on the modelled biomass. For FG, the range (0.04-0.17) is similar in absolute values (but opposite in sign) to the range for ingestion scaling. However, for two of the sites, FSC ( -0.04 to 0.04$)$ and $\mathrm{OM}(-0.01$ to 0.06$)$, the range spans zero, corresponding to no scaling with biomass, and the limits are small in magnitude. The scaling of $b_{\mathrm{r}}$ should not, however, be construed as the scaling of specific respiration rate, defined here as the total respiration within a size class divided by the total biomass within that size class. As with the model representation of mortality, the behaviour of specific respiration rate with size in the model cannot be inferred from a single parameter. Equation (1) indicates that the scaling of the specific respiration rate is given by the sum of the scaling 
Table 5. Scaling exponents derived from model output, assuming a scaling of parameter $=a W^{b}$, where $W$ is nominal weight for class. For biomass, observed scalings are also given, in parentheses in italics.

\begin{tabular}{|c|c|c|c|c|c|c|}
\hline & \multicolumn{2}{|c|}{ Faroe-Shetland Channel } & \multicolumn{2}{|c|}{ Fladen Ground } & \multicolumn{2}{|c|}{ Oman Margin } \\
\hline & best fit & range & best fit & range & best fit & range \\
\hline Biomass & $0.32(0.32)$ & $(0.31,0.33)$ & $0.18(0.16)$ & $(0.18,0.19)$ & $0.20(0.12)$ & $(0.19,0.21)$ \\
\hline Specific mortality & -0.12 & $(-0.17,-0.09)$ & -0.25 & $(-0.25,-0.11)$ & -0.13 & $(-0.26,-0.12)$ \\
\hline Specific respiration & -0.10 & $(-0.20,-0.05)$ & -0.08 & $(-0.17,0.1)$ & -0.14 & $(-0.19,-0.13)$ \\
\hline Individual respiration & 0.90 & $(0.80,0.95)$ & 0.92 & $(0.83,0.9)$ & 0.86 & $(0.81,0.87)$ \\
\hline
\end{tabular}

exponents $b_{\mathrm{g}}$ and $b_{\mathrm{r}}$, i.e. the compound effect of allometry allowed in assimilation and respiration efficiencies. Although the scaling exponent of assimilation (via $g_{i}$ ) is constrained to be zero or negative, that for the respired fraction of assimilation $\left(b_{\mathrm{r}}\right)$ can be positive or negative, so in theory the specific respiration rate is free to scale either way with size or not at all. A caveat to this is that, as described in Sect. 2.4, an additional observationally motivated criterion is applied to ensure that total respiration within a size class increases with size. As respiration is the product of specific rate and biomass, this condition imposes that $b_{\mathrm{g}}+b_{\mathrm{r}}+b_{\mathrm{B}}$ is greater than zero, where $b_{\mathrm{B}}$ is the scaling exponent for biomass. Table 5 shows that for all three sites, for the best fit, the scaling exponent for specific respiration rate is negative. There is, however, considerable variability in the estimated rate. At FG, the range $(-0.17$, 0.10) straddles zero and six of the ten optimizations give a positive scaling exponent. At FSC the scaling varies from near zero, but negative, down to -0.20 . At OM, the range is tighter and significantly different from zero $(-0.19,-0.13)$. Focusing on particular values of the specific respiration rate, for FSC and OM the smallest size class has a specific respiration rate between $0.3 \times 10^{-2}$ and $2.1 \times 10^{-2} \mathrm{day}^{-1}$ while the largest has a rate between $0.5 \times 10^{-3}$ and $5.2 \times 10^{-3}$ day $^{-1}$. At FG, because of the greater range of scaling behaviour across the optimizations, the specific respiration rate varies between $0.6 \times 10^{-3}$ and $7.4 \times 10^{-3}$ day $^{-1}$ for the smallest size class and a similar range of between $1.1 \times 10^{-3}$ and $5.9 \times 10^{-3}$ day $^{-1}$ for the largest.

We can also calculate the scaling of the fluxes through the system for each size class, by substituting values from Table 3 into Eq. (1). Table 6 shows the scaling parameters for the three fluxes of ingestion, mortality and respiration. Although the scaling is negative in one instance, this is very close to zero. All other scalings are positive. For FG and OM the flux scalings are sufficiently close to zero that the biomass scaling is effectively cancelling that of ingestion and mortality. For FS the increase of biomass with size dominates to give the fluxes similar behaviour, despite specific rates (Table 5) decreasing with size.
Table 6. Scaling of flux terms in Eq. (1) with size for the three study sites.

\begin{tabular}{lccc}
\hline Flux scalings & $\begin{array}{c}\text { Faroe-Shetland } \\
\text { Channel }\end{array}$ & $\begin{array}{c}\text { Fladen } \\
\text { Ground }\end{array}$ & $\begin{array}{c}\text { Oman } \\
\text { Margin }\end{array}$ \\
\hline Ingestion flux & 0.21 & 0.00 & 0.07 \\
Mortality flux & 0.20 & -0.07 & 0.07 \\
Respiration flux & 0.22 & 0.11 & 0.06 \\
\hline
\end{tabular}

\subsection{Non-allometric model parameters and estimates}

The fraction of ingestion that is assimilated, $\alpha$, is allowed a wide range and the optimizer exploits this. There is little consistency, either between or within sites (Table 3), with the range of fitted values across the 10 optimizations for each site spanning the available range. As the parameter only occurs in the model Eqs. (1) and (3) as a product with the prefactor of $g_{i}, a_{\mathrm{g}}$, it might be thought that the variability reflects the inability to constrain both parameters independently. However, the product $\alpha a_{\mathrm{g}}$ shows similar variability to $\alpha$ (not shown) and so the uncertainty also reflects the inability to adequately constrain this parameter by fitting the model purely to data for biomass.

As mentioned earlier, the optimizer can only estimate the POC flux available to metazoans in the size classes studied. For this reason, the fitted values for the parameter $Q$ (Table 3) represent a lower bound on the total POC flux. Although the value for the best fit at the three sites is reasonably consistent within $4-16 \mathrm{gC} \mathrm{m}^{-2} \mathrm{yr}^{-1}$, there is typically a factor of 20 variation across the 10 optimizations at a given site, though for no optimization does the value hit one of the bounds for the allowed range. Nevertheless, based on the model results there is no justification for claiming variation in the total POC flux between the sites and the only thing that can be said with a degree of confidence is that the total POC flux is likely to be above $1 \mathrm{gC} \mathrm{m}^{-2} \mathrm{yr}^{-1}$.

The model values for the POC stock in the sediment for the three stations are very similar: $3.9-52 \times 10^{-4}, 1.5-15 \times$ $10^{-4}$ and $0.8-18 \times 10^{-4} \mathrm{gC} \mathrm{m}^{-2}$ for FS, FG and OM sites respectively. Unfortunately, we have no suitable data to compare these values to. Note that the model POC stock in the sediment is only that immediately usable to the 
modelledorganisms. In practice the dominant part of the stock will be more refractory material. This is not modelled here and so model sediment stock values should not be regarded as estimates for total POC in sediment.

\section{Discussion}

\subsection{Controls on the biomass size spectra}

The data presented here add to a rare collection of observed biomass size spectra in marine benthic communities, especially in the deep sea. Such scarcity of data makes it difficult to assess how conservative biomass distributions are in time and space. The few available studies suggest that spatial and temporal variability appears to be minimal (Schwinghamer, 1981, 1983, 1985; Drgas et al., 1998; Duplisea, 2000). Consequently, we have chosen to adopt the Occam's Razor simplicity approach by assuming a steady-state system in our modelling study. Questions therefore remain concerning how temporal variation in the POC flux, for instance on seasonal timescales, might affect biomass spectra. An obvious future study using the model presented here would be to explore this.

Our field data (Fig. 3) and model results (Fig. 4), drawn from highly contrasting environments, suggest a continuous increasing distribution of biomass across the size classes studied. These observations are consistent with the earlier works of Drgas et al. (1998) and Duplisea (2000), and accepting the potential sampling artefacts described by Bett (2013), also with the classical works of Schwinghamer (1981, 1983, 1985). This increase in biomass with body size is also apparent in studies of the larger benthos (megabenthos) by Lampitt et al. (1986) and Thurston et al. (1994).

The assumption of steady state allows us to probe the controls on the scaling of biomass, as in this instance the model is easily solved mathematically. From Eqs. (1) and (3) we can derive

$B_{i}=\left(1-r_{i}\right) \alpha g_{i} R / m_{i}$.

For FSC and OM, $r_{i}$ scales relatively weakly with body size (Table 3 ), so the scaling of $B_{i}$ is dictated by the ratio

$g_{i} / m_{i}=\left(a_{\mathrm{g}} / a_{\mathrm{m}}\right) M^{b_{\mathrm{g}}-b_{\mathrm{m}}}$,

i.e. the slope of the biomass spectrum is $\sim b_{\mathrm{g}}-b_{\mathrm{m}}$. It is only when the scaling of $r_{i}$ is so small, though, that Eq. (4) predicts a relationship so close to such a power law. For FG, the scaling of $r_{i}$ is more significant. However, even in this case, if a scaling is calculated for the model, as for the observations, by carrying out a regression of $\log$ (biomass) versus $\log$ (size), the regression line is indistinguishable from the model output and hence not visible in Fig. 4. For FG the regression exponent is typically $13-36 \%$ smaller than that which would be estimated using $b_{\mathrm{g}}-b_{\mathrm{m}}$. For FSC (3-10\%) and OM (1-23\%) the difference in the two estimates is smaller in magnitude and varying in sign. The above discussion indicates that to first order the scaling of the biomass spectrum is set by a balance between the influences of mortality and ingestion. We now discuss the allometry of each of these two processes in turn.

\subsection{Mortality}

It should be remembered that the modelled allometry of mortality, with specific rate decreasing with size, is imposed in the model. Schwinghamer (1983) suggested that biomass concentrates in larger species of benthic organisms on account of their greater longevity, providing support for sizebased mortality. Support for the allometric scaling of mortality also comes from studies in both terrestrial (Marba et al., 2007) and pelagic systems (Peterson and Wroblewski, 1984; McGurk, 1986; Savage et al., 2004), most of which have suggested quarter power scaling. Fenchel's (1974) classical work on the intrinsic rate of natural increase (the $r_{\mathrm{m}}$ "Malthusian parameter") suggests a body size scaling power of -0.275 . It might be reasonable to assume that it is matched by a similar power of scaling for mortality rate. As noted already, the specific mortality scaling parameters for the three sites studied here are too variable to make any claim regarding their match to a quarter power scaling (Table 5).

There is currently no direct evidence for density dependent mortality in benthic communities, as applied in this model. However, density-dependent mortality may arise from factors such as pathogens, starvation and predation and this modelling approach enables an investigation of controls on biomass size spectra without the need for increased degrees of freedom (and thus uncertainty) that would result from the addition of poorly known parameters and terms to account for niche specialization. One may speculate that the single-dimensional niche model developed by Williams and Martinez (2000), and used extensively in food web studies, may in practice lead to the density dependencies in mortality used in the current model. However, the lack of predation (see Sect. 4.2) within the size range considered in this study makes the application of such a model of doubtful use.

The model results, indicating that mortality rather than respiration may be the more important factor in determining benthic biomass size spectra, are not necessarily inconsistent with the predictions of the metabolic theory of ecology. First, Brown et al. (2004) show evidence for $a-1 / 4$ power law for specific mortality (this is considered in greater detail by Savage et al., 2004). Although a stronger scaling than that found by the model at FSC, this is within the model range at FG and OM. Second, it is possible to estimate the respiration per individual predicted by the model, by the simple expedient of dividing the total respiration for a size class by the number of organisms within that size class. The latter can be estimated by dividing the total biomass by the representative weight for that size class. The scaling of the esti- 
mated individualrespiration rate is also shown in Table 5. Although it is stronger than the $3 / 4$ power generally employed in metabolic theory (Brown et al., 2004) at each of the sites, it differs from the classical scaling of $2 / 3$ based on surface area to volume ratio by a greater margin.

The importance of size-specific mortality in the Peters (1983) model has recently been acknowledged in an application investigating the influence of hypoxia on subtidal macrofauna (Rakocinski, 2009). However, that study used a timedependent version of the Peters model in which the mortality was not density dependent, leading to competitive exclusion and hence to the survival of only one size class at equilibrium. Rakocinski (2009) showed that the effects of oxygen limitation favoured a less even distribution of biomass among size classes with more biomass accumulating in the larger size classes. We chose not to adopt a similar approach for the OM site because we wished to test the null hypothesis that a single simple model based on allometry can reproduce observed biomass spectra at contrasting sites. Regardless, the high variability in our data for OM would not lend itself to testing the validity of different parameterizations.

In the model, the density-dependent mortality term (Eq. 1) enables coexistence of the multiple size classes on a single food source. Although an accepted approach (Brown, 1989; Chesson, 2000), it does not explicitly address the reasons for species coexistence in benthic systems.

\subsection{Ingestion}

Ingestion has been shown to scale with body size in the benthos (Cammen, 1980). Production and respiration (metabolism) are also known to scale with body size (e.g. Brown et al., 2004; Banse and Mosher, 1980). In addition, there is evidence that food selection is size dependent (Ritchie and Olff, 1999) whereby small animals can select small patches with high-quality food, and larger animals can rely on larger patches of food that are of overall lower quality. The approach of Ritchie and Olff (1999) relies on assuming a fractal geometry of the environment. While the orders of magnitude that span the size range of the fauna considered in the present study (Table 2) may lend themselves to such an approach, data on the relevant fractal dimensions of both the habitat and resources are generally lacking for benthic data sets. In addition, Hildrew et al. (2007) suggest that the fractal dimension of a habitat may not be as important as factors relating body size to biological characteristics in marine benthic assemblages. Furthermore, the role of food selection in determining the biomass size spectra would require supporting information on the particular food preferences of the fauna in the present study's size range. To our knowledge, there are no studies of resource preferences at greater resolution than can be presently provided by isotope tracer techniques within the size range addressed in this study, although studies involving larger benthic organisms exist in both the deep-sea and shallow intertidal sediments (Wigham et al., 2003; Woulds et al., 2010). Hence, the modelling approach presented here neglects food selection and assumes that all the size classes share a common food source. However, if food selectivity is size dependent at the three sites, this may imply that the assimilation efficiency $(\alpha)$ should also be allowed to scale with body size, particularly as lower quality food tends to favour lower assimilation efficiencies (Ahrens et al., 2001). However, in the model $\alpha$ only occurs as a product with the ingestion rate $g$ and so optimizing to the observations may implicitly include any scaling of assimilation in the scaling of ingestion already.

The few studies on benthic assimilation and body size suggest that larger organisms have higher assimilation efficiency because of increased gut passage time which is thought to permit a relatively more complete digestion of food material (Jumars et al., 1990; Gage and Tyler, 1991). While more extensive reviews across the animal kingdom suggest that assimilation efficiencies do not scale with body size (see Hendriks, 1999), the only published size-based benthic assimilation efficiencies for deposit feeders (Ahrens et al., 2001) suggest otherwise.

\subsection{Predation}

Our approach has assumed a negligible role of direct predation (species $\mathrm{X}$ consumes species $\mathrm{Y}$ ) in determining the biomass spectrum. However, it should be noted that passive predation (species $\mathrm{X}$ consumes many smaller species by its general feeding action) almost certainly happens, although the extent and the impact on biomass size spectra is unknown. Where targeted pelagic predation on detrital communities has been modelled, the impact on the benthic system is non-negligible (Blanchard et al., 2009). The latter have shown that there is a steep decline in the abundance size spectrum for detritivores $>1 \mathrm{~g}$ in size when top-down pelagic predation is included. This threshold size for the impact of predation is more than 30 times greater than the largest size class $(32 \mathrm{mg})$ considered in this study and may reflect that smaller-sized benthic organisms (as in our samples, $0.001-32 \mathrm{mg} \mathrm{wwt}$ ) are not generally considered the target prey size of most pelagic predators, although passive ingestion may occur. If passive predation is important, one can speculate that such predation will be size dependent, i.e. larger deposit feeders will by their general feeding action consume smaller individuals. The current approach to modelling marine (pelagic) biomass size spectra in which targeted predation occurs is to use predator-prey ratios (Kerr and Dickie, 2001). However, it is not at all clear how this might be implemented in the present model given that the larger detritivores in our sample range (Table 2) may be passively grazing on benthic organisms one to three orders of magnitude smaller than themselves. This introduces a continuous range of possible predator-prey ratios and thus additional degrees of freedom, adding uncertainty in the model. Our model, in effect, incorporates passive predation as part of 
the "natural mortality", with the biomass transfer occurring via the common food pool.

\subsection{POC}

The model only estimates the fraction of POC flux reaching the seafloor that is consumed by the metazoans it explicitly represents. The rest of the sinking flux is assumed to be consumed by smaller or larger organisms or sequestered in the sediment. Dominance by bacteria of the breakdown of sedimentary organic material has been documented in both coastal and deep-sea environments and may be associated with their ability to both survive prolonged periods of starvation and to mineralize organic material of different reactivities, in both the presence and absence of oxygen. Short-term (days) carbon processing measurements within the Pakistan Margin Oxygen Minimum Zone (depths $<1000 \mathrm{~m}$, Woulds et al., 2009; physical scales $40 \mathrm{~cm}^{2}$ seabed area) indicate that up to $75 \%$ of the experimentally added organic carbon is respired, most likely by bacteria and Foraminifera. At deeper sites, the percentage increases to $95 \%$ (Woulds et al., 2009). Some uncertainty exists in the role of the benthic bacteria in respiring organic carbon, as shown by two deep-sea studies at comparable depths: Witte et al. (2003a, b; physical scale $200-400 \mathrm{~cm}^{2}$ seabed area) found that macrofauna dominated the initial response to organic matter inputs in short-term experiments, whereas Moodley et al. (2002; physical scale $144 \mathrm{~cm}^{2}$ seabed area) showed that the microbial community was more important. It should also be noted that both studies reflect short-term responses (days to weeks) to food inputs and that a steady state may have not been achieved. The model used here assumes steady-state conditions. Furthermore, the area of seabed studied will likely influence the result - i.e. at small physical scales, bacteria are likely to dominate total community respiration, while at larger scales, organisms of greater body mass will become increasingly more significant in total community respiration. Note that in the present case our model estimates of the parameter $Q$ represent the POC flux that supports metazoans in classes 5-20. As our assumed lower limit for $f_{\text {other }}$ is 0.5 (see Table 3 ), the POC flux required to support the total benthic community will be at least twice $Q$.

Comparisons with other data are not straightforward, given that POC flux estimates are highly dependent on the methods used (Lampitt et al., 2001). For consistency and repeatability we instead refer to modelled POC flux to the seafloor (Table 1) as derived from Lutz et al. (2007). The latter model suggests values of 14.5 (FSC), 42.6 (FG) and $8.8(\mathrm{OM}) \mathrm{gC} \mathrm{m}^{-2} \mathrm{yr}^{-1}$, that would seem to match well with our $Q$ parameter estimates: 16,50 , and $13 \mathrm{gCm}^{-2} \mathrm{yr}^{-1}$ respectively. It is encouraging that both the absolute order of magnitude, and the relative magnitude between study sites are consistent between our estimate of benthic flux consumption and the Lutz et al. (2007) based estimate. Nevertheless these data suggest a substantial potential deficit in the flux supplied relative to total flux consumed (i.e. consumed is roughly twice that supplied). Similar deficits have been measured in deep-sea field studies (Smith Jr. et al., 2009). These apparent deficits may arise from a number of causes such as technical difficulties in measuring POC flux (Lampitt et al., 2001), and mismatches in the temporal and spatial (see Sect. 4.3) scales of observations. Smith et al. (2013) have recently suggested that previous findings of food deficits are compensated by large episodic surpluses in POC that provide a balance over longer timescales. For the present, an inverse analysis (e.g. van Oevelen et al., 2006a, b) of benthic standing stocks and their power demand, may be a more reliable measure of POC flux to the seabed than water column measurements by sediment trap.

\subsection{Correlations in parameters}

The most direct constraint of the data on the model is through biomass. It was shown in Sect. 4.1 that the scaling of biomass is set to first order by the difference in scaling exponents for ingestion and mortality. This leaves a degree of freedom such that if $b_{\mathrm{g}}$ and $b_{\mathrm{m}}$ are increased by the same amount, then the biomass scaling of the model remains the same. Although this is borne out by a strong correlation of these two parameters for FG and OM, their correlation is only 0.69 at FSC.

More generally, defining a strong correlation as one greater than 0.7 in magnitude (corresponding to each explaining greater than $50 \%$ of the variance in the other), the number of strongly correlated parameters varies between sites: for FG there are five $\left(-0.75\right.$ for $\alpha-b_{\mathrm{g}} ;+0.92$ for $b_{\mathrm{g}}-b_{\mathrm{m}} ;+0.86$ for $b_{\mathrm{g}}-a_{\mathrm{m}} ;+0.96$ for $b_{\mathrm{m}}-a_{\mathrm{m}} ;+0.72$ for $\left.f_{\text {other }}-\mathrm{POC}_{\text {flux }}\right)$; for FSC there are three $\left(+0.72\right.$ for $b_{\mathrm{g}}-b_{\mathrm{r}}$; +0.98 for $b_{\mathrm{m}}-a_{\mathrm{m}} ;+0.85$ for $\left.f_{\text {other }}-\mathrm{POC}_{\text {flux }}\right)$; for OM there are nine $\left(-0.92\right.$ for $b_{\mathrm{g}}-b_{\mathrm{r}} ;+0.98$ for $b_{\mathrm{g}}-b_{\mathrm{m}} ;-0.73$ for $b_{\mathrm{g}}-a_{\mathrm{r}} ;+0.97$ for $b_{\mathrm{g}}-a_{\mathrm{m}} ;-0.96$ for $b_{\mathrm{r}}-b_{\mathrm{m}} ;-0.89$ for $b_{\mathrm{r}}-a_{\mathrm{m}} ;-0.79$ for $b_{\mathrm{m}}-a_{\mathrm{r}} ;+0.96$ for $b_{\mathrm{m}}-a_{\mathrm{m}} ;-0.79$ for $\left.a_{\mathrm{r}}-a_{\mathrm{m}}\right)$.

There is only one pairing that is strongly correlated across all sites, $b_{\mathrm{m}}-a_{\mathrm{m}}$, and this correlation is always positive. Since increasing $a_{\mathrm{m}}$ can maintain the median value of $a_{\mathrm{m}} W^{\mathrm{bm}}$ if $b_{\mathrm{m}}$ (which is negative) is increased, this reflects a degree of flexibility in setting the mortality of largest and smallest classes. Unfortunately this strongest correlation exists for perhaps the most difficult to measure parameters. Correlations seen between $b_{\mathrm{g}}$ and $a_{\mathrm{m}}$ are related to the correlations of $b_{\mathrm{g}}-b_{\mathrm{m}}$ and $b_{\mathrm{m}}-a_{\mathrm{m}}$.

The next most consistent correlation is a positive one between $f_{\text {other }}$ and $\mathrm{POC}_{\text {flux }}(+0.72, \mathrm{FG} ;+0.85$, FSC; 0.62, $\mathrm{OM})$. This is expected as only the product $Q=(1-$ $\left.f_{\text {other }}\right) \mathrm{POC}_{\text {flux }}$ can be constrained, leaving a degree of freedom such that increasing $f_{\text {other }}$ can compensate an increase in $\mathrm{POC}_{\text {flux }}$. Although other strong correlations exist in isolation, their lack of consistency across the sites (e.g. for $b_{\mathrm{g}}-b_{\mathrm{r}}$ +0.52 at $\mathrm{FG},+0.72$ at $\mathrm{FSC}$ and -0.92 at $\mathrm{OM}$ ) cautions 
against reading too much into them given the variability in the data and simplicity of the model.

\subsection{Universality}

Although the structure of the model at the three sites studied was the same, the specific values for parameters varied (Table 3). It is interesting, however, that parameters that exhibit little variability (across optimizations) at individual sites are often broadly consistent across sites (e.g. $\left.b_{\mathrm{g}}, b_{\mathrm{m}}\right)$ whereas parameters that are very variable at a site can be equally variable at all sites (e.g. $\alpha, a_{\mathrm{g}}$ ). This is an indication that, despite its simplicity, the model still has more degrees of freedom than the observations can constrain. Nevertheless, given the reasonable agreement in the key scaling parameters between sites, one interpretation is that the model is capturing a more universal behaviour of benthic communities and that it may be possible to reproduce the observations at all three sites using a model with a single set of parameters, and only the incident POC flux varying between them. Future work will explore whether such a common model exists.

\subsection{Metabolic theory}

As detailed by Brown et al. (2004), the metabolic theory of ecology predicts a $1 / 4$ power scaling of biomass across geometric body size classes within a single trophic level. Absolute biomass per class scales with resource supply (e.g. POC flux) and inversely with temperature, but the slope of the log-log plot of biomass on body size remains constant at $1 / 4$. Arguably derived by substantially different means, our model is broadly in agreement given the variability in the data, predicting a slope of 0.18-0.31 across our three study sites, that span a substantial environmental range (water depth, $150-1600 \mathrm{~m}$; habitat temperature -1 to $13^{\circ} \mathrm{C}$; oxygen concentration, $0.1-6 \mathrm{mLL}^{-1}$; POC flux, 9-43 $\mathrm{gC} \mathrm{m}^{-2} \mathrm{yr}^{-1}$ ). This may of course be coincidence, but it at least suggests the value of further study of macroecology as applied to the marine benthos.

\section{Summary}

The purpose of this work was to investigate benthic biomass distributions in marine assemblages (meio- to macro-fauna, $1 \mu \mathrm{g}-32 \mathrm{mg}$ ) to test the hypothesis that observed scaling of biomass spectra can be explained from an allometric basis. Our study adds to a sparse collection of observed biomass size spectra in benthic communities, particularly in the deep sea, and involves a rare application of simple allometric modelling to these environments. At all three sites studied, the metazoan fauna was dominated by deposit feeding meiofauna (nematodes) and macrofauna (polychaetes). The model reproduced the observed increase of biomass with body size at all three sites, indicating that a balance between sizespecific mortality and ingestion controls benthic biomass dis- tributions. Given the overall trends in published data, showing that biomass tends to increase with body size across geometric size classes, we speculate that this is a more widely applicable conclusion for marine sediments.

Acknowledgements. This work was a component of Oceans 2025, a major 5-year coordinated marine science programme funded by the Natural Environment Research Council (NERC). The contributions of Marcinko, Martin and Yool were facilitated by NERC NC modelling and that of Bett by NERC NC mapping funding. The cruises onboard the NERC research ship RRS Charles Darwin were ably supported by NERC's marine and seagoing technical support services, to whom we express our considerable thanks. We are also especially grateful to the Masters and crews of the vessel. We are indebted to Daniel O. B. Jones for implementing and running the Lutz et al. (2007) algorithm as employed in this contribution. Finally, we thank Paul Tyler and Henry Ruhl for their comments on earlier versions of the paper.

Edited by: J. Middelburg

\section{References}

Ahrens, M. J., Hertz, J., Lamoureux, E. M., Lopez, G. R., McElroy, A. E., and Brownawell, B. J.: The effect of body size on digestive chemistry and absorption efficiencies of food and sedimentbound organic contaminants in Nereis succinea (polychaeta), J. Exp. Mar. Biol. Ecol., 263, 185-209, 2001.

Anderson, T. R. and Pondaven, P.: Non-Redfield carbon and nitrogen cycling in the Sargasso Sea: pelagic imbalances and export flux, Deep-Sea Res. Pt. I, 50, 573-591, 2003.

Banse, K. and Mosher, S.: Adult body-mass and annual production/biomass relationships of field populations, Ecol. Monogr., 50, 355-379, 1980.

Benoit, E. and Rochet, M.-J.: A continuous model of biomass size spectra governed by predation and the effects of fishing on them, J. Theor. Biol., 226, 9-21, 2004.

Bett, B. J.: UK Atlantic margin environmental survey: introduction and overview of bathyal benthic ecology, Cont. Shelf Res., 21, 917-956, 2001.

Bett, B. J.: Characteristic benthic size spectra: potential sampling artefacts, Mar. Ecol.-Prog. Ser., 487, 1-6, 2013.

Bett, B. J.: Macroecology and meiobenthos: reply to Warwick (2014), Mar. Ecol.-Prog. Ser., 505, 299-302, 2014.

Billett, D. S. M., Bett, B. J., Jacobs, C. L., Rouse, I. P., and Wigham, B. D.: Mass deposition of jellyfish in the deep Arabian Sea, Limnol. Oceanogr., 51, 2077-2083, 2006.

Blanchard, J. L., Jennings, S., Law, R., Castle, M. D., McCloghrie, P., Rochet, M.-J., and Benoît, E.: How does abundance scale with body size in coupled size-structured food webs?, J. Anim. Ecol., 78, 270-280, 2009.

Blanco, J. M., Quiñones, R. A., Guerrero, F., and Rodriguez, J.: The use of biomass spectra and allometric relations to estimate respiration of planktonic communities, J. Plankton Res., 20, 887-900, 1998.

Brey, T., Müller-Wiegmann, C., Zittier, Z. M. C., and Hagen, W.: Body composition in aquatic organisms - A global data bank of 
relationships between mass, elemental composition and energy content, J. Sea Res., 64, 334-340, 2010.

Brown, J. H., Gillooly, J. F., Allen, A. P., Savage, V. M., and West, G. B.: Toward a metabolic theory of ecology, Ecology, 85, 1771-1789, 2004.

Brown, J. S.: Coexistence on a seasonal resource, Am. Nat., 133, 168-182, 1989.

Cammen, L. M.: Ingestion rate: an empirical-model for aquatic deposit feeders and detritivores, Oecologia, 44, 303-310, 1980.

Cammen, L. M.: The relationship between ingestion rate of deposit feeders and sediment nutritional value, in: Ecology of Marine Deposit Feeders, Lecture Notes on Coastal and Estuarine Studies, edited by: Lopez, G., Taghon, G., and Levinton, J., SpringerVerlag, New York, USA, 201-222, 1989.

Chapelle, G. and Peck, L. S.: Polar gigantism dictated by oxygen availability, Nature, 399, 114-115, 1999.

Chesson, P.: Mechanisms of maintenance of species diversity, Annu. Rev. Ecol. Syst., 31, 343-366, 2000.

de Wilde, P. A. W. J., Berghuis, E. M., and Kok, A.: Biomass and activity of benthic fauna on the Fladen Ground (Northern North Sea), Neth. J. Sea Res., 20, 313-323, doi:10.1016/00777579(86)90053-0, 1986.

Dickie, M., Kerr, S. R., and Boudreau, P.: Size-dependent processes underlying regularities in ecosystem structure, Ecol. Monogr., 57, 233-250, 1987.

Drgas, A., Radziejewska, T., and Warzocha, J.: Biomass size spectra of near-shore shallow-water benthic communities in the Gulf of Gdańsk Southern Baltic Sea, Mar. Ecol., 19, 209-228, 1998.

Duplisea, D. E.: Benthic organism biomass size-spectra in the Baltic Sea in relation to the sediment environment, Limnol. Oceanogr., 45, 558-568, 2000.

Fenchel, T.: Intrinsic rate of natural increase: the relationship with body size, Oecologia, 14, 317-326, 1974.

Gage, J. D. and Bett, B. J.: Deep-sea benthic sampling, in: Methods for the study of marine benthos, edited by: Eleftheriou, A. and McIntyre, A., Blackwell, Oxford, UK, 273-325, 2005.

Gage, J. D. and Tyler, P. A.: Deep-sea biology: A natural history of organisms at the deep-sea floor, Cambridge University Press, Cambridge, UK, 1991.

Glazier, D. S.: Beyond the "3/4-power law": variation in the intraand interspecific scaling of metabolic rate in animals, Biol. Rev. Camb. Philos., 80, 611-662, 2005.

Gooday, A. J., Bett, B. J., Escobar-Briones, E., Ingole, B., Levin, L. A., Neira, C., Raman, A. V., and Sellanes, J.: Habitat heterogeneity and its influence on benthic biodiversity in oxygen minimum zones, Mar. Ecol., 31, 125-147, 2010.

Griesbach, S., Peters, R. H., and Youakim, S.: An allometric model for pesticide bioaccumulation, Can. J. Fish. Aquat. Sci., 39, 727-735, 1982

Hargrave, B. T.: Energy budget for a deposit-feeding amphipod, Limnol. Oceanogr., 16, 99-103, doi:10.4319/lo.1971.16.1.0099, 1971.

Henriks, A. J.: Allometric scaling of rate, age and density parameters in ecological models, Oikos, 86, 293-310, 1999.

Hessler, R. R. and Jumars, P. A.: Abyssal community analysis from replicate box cores in the central North Pacific, Deep-Sea Res. Pt. I, 21, 185-209, 1974.

Heip, C., Vincx, M., and Vranken, G.: The ecology of marine nematodes, Oceanogr. Mar. Biol., 23, 399-489, 1985.
Hildrew, A., Raffaelli, D., and Edmonds-Brown, R.: Body size: The structure and function of aquatic systems, Cambridge University Press, Cambridge, UK, 2007.

Jumars, P. A., Mayer, L. M., Deming, J. W., Baross, J. A., and Wheatcroft, R. A.: Deep-sea deposit-feeding strategies suggested by environmental and feeding constraints, Philos. T. R. Soc. S. A, 331, 85-101, 1990.

Kaariainen, J. I.: Investigating and modeling the size structure of benthic communities, University of Southampton, School of Ocean and Earth Science, PhD thesis, 210 pp., 2006.

Kerr, S. R. and Dickie, L. M.: The biomass spectrum: a predatorprey theory of aquatic production, Columbia University Press, New York, USA, 2001.

Lampitt, R. S., Billett, D. S. M., and Rice, A. L.: Biomass of invertebrate megabenthos from 500 to $4100 \mathrm{~m}$ in the northeast Atlantic Ocean, Mar. Biol., 93, 69-81, 1986.

Lampitt, R. S., Bett, B. J., Kiriakoulakis, K., Popova, E. E., Ragueneau, O., Vangriesheim, A., and Wolff, G. A.: Material supply to the abyssal seafloor in the northeast Atlantic, Prog. Oceanogr., 50, 27-63, doi:10.1016/S0079-6611(01)00047-7, 2001.

Lutz, M. J., Caldeira, K., Dunbar, R. B., and Behrenfeld, M. J.: Seasonal rhythms of net primary production and particulate organic carbon flux to depth describe the efficiency of biological pump in the global ocean, J. Geophys. Res., 112, C10011, doi:10.1029/2006JC003706, 2007.

Marba, N., Duarte, C. M., and Agusti, S.: Allometric scaling of plant life history, P. Natl. Acad. Sci. USA, 104, 15777-15780, 2007.

McGurk, M. D.: Natural mortality of marine pelagic fish eggs and larvae - role of spatial patchiness, Mar. Ecol.-Prog. Ser., 34 227-242, 1986.

Minto, C., Myers, R. A., and Blanchard, W.: Survival variability and population density in fish populations, Nature, 452, 344-347, doi:10.1038/nature06605, 2008

Moodley, L., Middelburg, J. J., Boschker, H. T. S., Duineveld, G. C. A., Pel, R., Herman, P. M. J., and Heip, C. H. R.: Bacteria and foraminifera: key players in a short-term deep-sea benthic response to phytodetritus, Mar. Ecol.-Prog. Ser., 236, 23-29, 2002.

Ohman, M. D. and Hirche, H. J.: Density-dependent mortality in an oceanic copepod population, Nature, 412, 638-641, doi:10.1038/35088068, 2001.

Peters, R. H.: The ecological implications of body size, Cambridge University Press, Cambridge, UK, 1983.

Peterson, I. and Wroblewski, J. S.: Mortality rate of fishes in the pelagic ecosystem, Can. J. Fish. Aquat. Sci., 41, 1117-1120, 1984.

Pfannkuche, O., Boetius, A., Lochte, K., Lundgreen, U., and Thiel, H.: Responses of deep-sea benthos to sedimentation patterns in the north-east Atlantic in 1992, Deep-Sea Res. Pt. I,, 46, 573-596, 1999.

Quiroga, E., Quinoñes, R., Palma, M., Sellanes, J., Gallardo, V., Gerdes, D., and Rowe, G.: Biomass size-spectra of macrobenthic communities in the oxygen minimum zone off Chile, Estuar. Coast. Shelf S., 62, 217-231, 2005.

Rakocinski, C. F.: Linking allometric macrobenthic processes to hypoxia using the Peters mass balance model, J. Exp. Mar. Biol Ecol., 381, S13-S20, doi:10.1016/j.jembe.2009.07.005, 2009. 
Ritchie, M. E. and Olff, H.: Spatial scaling laws yield a synthetic theory of biodiversity, Nature, 400, 557-560, 1999.

Savage, V. M., Gillooly, J. F., Brown, J. H., West, G. B., and Charnov, E. L.: Effects of body size and temperature on population growth, Am. Nat., 163, 429-441, 2004.

Schwinghamer, P.: Characteristic size distributions of integral benthic communities, Can. J. Fish. Aquat. Sci., 38, 1255-1263, 1981.

Schwinghamer, P.: Generating ecological hypotheses from biomass spectra using causal analysis: a benthic example, Mar. Ecol.Prog. Ser., 13, 151-166, 1983.

Schwinghamer, P.: Observations on size-structure and pelagic coupling of some shelf and abyssal benthic communities, in: Proceedings of the Nineteenth European Marine Biology Symposium, edited by: Gibbs, P. E., Cambridge University Press, Cambridge, UK, 347-359, 1985.

Schwinghamer, P., Hargrave, B., Peer, D., and Hawkins, C. M.: Partitioning of production and respiration among size groups of organisms in an intertidal benthic community, Mar. Ecol.-Prog. Ser., 31, 131-142, 1986.

Schmidt-Nielsen, K.: Scaling - why is animal size so important?, Cambridge University Press, Cambridge, UK, 1984.

Smith, K. L., Ruhl, H. A., Bett, B. J., Billett, D. S. M., Lampitt, R. S., and Kaufmann, R. S.: Climate, carbon cycling, and deepocean ecosystems, P. Natl. Acad. Sci. USA, 106, 19211-19218, 2009.

Smith Jr., K. L., Ruhl, H. A., Kahru, M., Huffard, C. L., and Sherman, A. D.: Deep ocean communities impacted by changing climate over $24 \mathrm{y}$ in the abyssal northeast Pacific Ocean, P. Natl. Acad. Sci. USA, 110, 19838-19841, doi:10.1073/pnas.1315447110, 2013.

Strayer, D.: The size structure of a lacustrine zoobenthic community, Oecologia, 69, 513-516, 1986.

Thurston, M. H., Bett, B. J., Rice, A. L., and Jackson, P. A. B.: Variations in the invertebrate abyssal megafauna in the North Atlantic Ocean, Deep-Sea Res. Pt. I, 41, 1321-1348, 1994.

Turrell, W. R., Slesser, G., Adams, R. D., Payne, R., and Gillibrand, P. A.: Decadal variability in the composition of Faroe Shetland Channel bottom water, Deep-Sea Res. Pt. I, 46, 1-25, 1999. van Oevelen, D., Soetart, K., Middelburg, J. J., Herman, P. M. J., Moodley, L., Hamels, I., Moens, T., and Heip, C. H. R.: Carbon flows through a benthic food web: integrating biomass, isotope and tracer data, J. Mar. Res., 64, 453-482, 2006 a.

van Oevelen, D., Moodley, L., Soetart, K., and Middelburg, J. J.: The trophic significance of bacterial carbon in a marine intertidal sediment: results of an in situ stable isotope labeling study, Limnol. Oceanogr., 51, 2349-2359, 2006b.

Ward, B. A., Friedrichs, M. A. M., Anderson, T. R., and Oschlies, A.: Parameter optimisation techniques and the problem of underdetermination in marine bio-geochemical models, J. Marine Syst., 81, 34-43, 2010.

Warwick, R. M.: Species size distributions in marine benthic communities, Oecologia, 61, 32-41, 1984.

Warwick, R. M.: Meiobenthos and macrobenthos are discrete entities and not artefacts of sampling a size continuum: Comment on Bett (2013), Mar. Ecol.-Prog. Ser., 505, 295-298, 2014.

Wigham, B. D., Hudson, I. R., Billett, D. S. M., and Wolff, G. A.: Is long term change in the abyssal Northeast Atlantic driven by qualitative changes in export flux? Evidence from selective feeding in deep-sea holothurians, Prog. Oceanogr., 59, 409-441, 2003.

Williams, R. J. and Martinez, N. D.: Simple rules yield complex food webs, Nature, 404, 180-183, 2000.

Witte, U., Wenzhofer, F., Sommer, S., Boetius, A., Heinz, P., Aberle, N., Sand, M., Cremer, A., Abraham, W. R., Jorgensen, B. B., and Pfannkuche, O.: In situ experimental evidence of the fate of a phytodetritus pulse at the abyssal sea floor, Nature, 424, 763-766, 2003a.

Witte, U., Aberle, N., Sand, M., and Wenzhofer, F.: Rapid response of a deep-sea benthic community to POM enrichment: an in situ experimental study, Mar. Ecol.-Prog. Ser., 251, 27-36, 2003 b.

Woulds, C., Cowie, G. L., Andersson, J. H., Middelburg, J. J., and Levin, L. A.: The short-term fate of organic carbon in marine sediments: comparing the Pakistan margin to other regions, DeepSea Res. Pt. II, 56, 393-402, 2009.

Woulds, C., Middelburg, J. J., and Cowie, G. L.: Alteration of organic matter during infaunal polychaete gut passage and links to sediment organic geochemistry. Part I: Amino acids, Geochim. Cosmochim. Ac., 77, 396-414, 2012. 